\title{
Residential Disadvantages and Disincentives: Examining a Black Proportion Paradox
}

\author{
Karl Vachuska
}

\begin{abstract}
:
Research on both neighborhood effects and segregation dynamics of Black Americans has focused on the significance of income and poverty levels in predominately black neighborhoods. In this article, I identify an assortment of disadvantages facing Black Americans that's presence is inversely related to the black proportion in neighborhoods as an additional source of residential disadvantage and disincentive and suggest a critical relationship between this set of disadvantages and the disadvantages that tend to be situated more so in predominately black neighborhoods. Besides suggesting the relationships between these two sets of disadvantages are significant in determining the net disadvantage black Americans are subjected to, I build on the findings of Bruch (2014), demonstrating via Interactive Markov Models and analysis of recent American Community Survey data that higher levels of Inversely-Related Disadvantages can have a positive effect on the neighborhood black proportion Affluent Blacks experience, but only when Between-Race Inequality is low.
\end{abstract}




\section{Introduction}

Following emancipation, Jim Crow laws disenfranchised blacks, which created a system of de jure segregation, subjecting blacks to inferior accommodations and opportunities at a national scale. The Jim Crow era was accompanied by a period of "racial terrorism" in which mass numbers of blacks were systematically attacked, brutalized, and lynched, effectively decimating many black communities. Following the end of the Jim Crow era in 1965, de jure segregation was succeeded by de facto racial segregation. Nonetheless, a significant increase in opportunities and better available resources allowed for a period of significant advancement for blacks, which manifested in significant declines in black poverty and unemployment rates, as well as the rapid expansion of the black middle-class. Despite this, evident inequalities between white and blacks remain to this day, and many inequalities that were shrinking have stagnated. Though historical factors contribute mainly to the many lasting racial inequalities, de facto racial segregation remains a central cause as well. So while racial segregation continues to be stark today, macrosegregation continues to decline despite this. (Frey 2015) In Illinois for instance, which boasts one of the largest black populations in the United States, $24.5 \%$ of Black Illinoisans live in census tracts that are less than $20 \%$ black, while another $41.5 \%$ of Black Illinoisans live in census tracts that are over $80 \%$ black. (United States Census Bureau) These statistics indicate significant shares of the 1.8 million Illinois black population live in vastly different racially composed neighborhoods.

Much research on the racial composition of neighborhoods has focused on the harmful effects of racial segregation, particularly in a macro-sociological sense. (Massey 1990, Krysan and Crowder 2017) A growing body of research, however, examines the disadvantages and adverse effects of racially integrated environments on blacks. (English et al. 2014) This research is primarily performed in an examination of educational institutions, but work also includes examinations of neighborhoods and workplaces. (Stainback and Irvin 2012, Solorzano 2000) 
In this paper, I will provide a selective overview of research on adverse effects of predominately non-black neighborhoods on blacks, as well as a briefer overview of research on the harmful effects of racially segregated neighborhoods on blacks. While reviewing both of these bodies of research, I will also examine evidence from other research which suggests many of these racially-dependent disadvantages play a direct role in how blacks choose what neighborhoods/communities in which to reside. I extrapolate these individual preference-findings to the macro-scale by analyzing how black preferences under different conditions may produce different degrees of segregation as modeled by empirically-grounded Interactive Markov Models. I compare the conclusions suggested by these simulations with data from the American Community Survey data on metropolitan-area specific shifts in segregation during the period from 2009 to 2016. In closing, I argue that many of the disadvantages blacks face today are dependent on neighborhood racial composition and that the arrangement and impact of racial composition-dependent disadvantages creates a compounding effect on how blacks are subjected to disadvantage, that overall has a much more detrimental impact that either set of disadvantage would independently.

\section{The Black Proportion Paradox:}

The body of disadvantages that blacks who reside in predominately black neighborhoods face spans several macro-sociological issues. Predominately black environments tend to have greater poverty and crime, as well as substantially inferior educational and economic opportunities (Massey 1990). These disadvantages have many significant impacts on Blacks' employment, income, and physical health, among other things. (Massey 1990) These disadvantages and impacts also affect blacks' residential preferences, as evident by Krysan and Farley's (2002) research, as well as current ongoing large-scale migrations such as Black Flight and the New Great Migration (Frey 2015). 
Blacks in predominately non-black neighborhoods face many disadvantages as well. Much research has focused on the set of issues facing black students at predominately white institutions (PWIs). These problems have manifested themselves for black students through disproportionately lower retention and graduation rates at PWI's. Characteristics of PWI's that are thought to be disadvantageous to black students are the prevalence of individual racism and microaggressions, isolation, alienation, and a general inferior racial climate. While these problems manifest themselves slightly differently in higher education, many of these same issues are significant disadvantages facing blacks at the neighborhood level. Research has identified racial discrimination (English et al. 2014), employer discrimination (Agan and Starr 2017) and a lack of black support (Vogt Yuan 2007, Terhune 2008), as disadvantages whose presence is inversely correlated with the black proportion in neighborhoods. Other researchers such as Krysan and Farley (2002) have identified certain disadvantages as factors behind why blacks have a low preference for neighborhoods with low black proportions. The significance of these factors is apparent given Krysan and Farley's (2002) finding that blacks have extremely low preferences for "all-white" neighborhoods.

Today, Blacks simultaneously face two significant sets of disadvantages, a set of disadvantages that tend to be worse in predominately black neighborhoods and a set of disadvantages that tend to be worse in predominately non-black neighborhoods. As expected as well, many of these disadvantages have significant salience to blacks as it relates to residential choices. Given the distinct nature of disadvantages found in predominately black neighborhoods compared to the disadvantages found in predominately non-black neighborhoods, it follows that these two sets of disadvantages are inversely related, that is neighborhoods that have a more significant presence of one of those two sets of disadvantages, generally has a lesser presence of the other set of disadvantages. In other words, even though neighborhood disadvantages facing blacks are stratified by black proportion, necessarily all neighborhoods will pose some significant or combination of 
significant sets of disadvantages. This arrangement of disadvantages becomes significant when it is recognized that these disadvantages are salient to black residents and affect black residential choices. Two inversely-related sets of disadvantages reduce the overall variance of utility between neighborhoods for black residents. If only one of the two sets of disadvantages existed, then either predominately black or predominately non-black neighborhoods would subject their black residents to disproportionately fewer disadvantages, and a majority of blacks would be able to choose the clearly better neighborhood choice, disproportionately improving the condition of black America compared to the fewer variant choices blacks actually have. In other words, the Black Proportion Paradox at the neighborhood level refers to the notion that the significance of the disadvantages blacks face at the neighborhood level is not just significant because of the disadvantage themselves but because of the way the disadvantages are arranged with black proportion and more generally racial composition.

Before elaborating further on the Black Proportion Paradox, I must first provide a comprehensive overview of the evidence that suggests the presence of disadvantages and disincentives that compose the Black Proportion Paradox. As stated earlier, my review will primarily focus on the disadvantages facing Blacks in predominately non-black neighborhoods, as the disadvantages Blacks face in predominately black neighborhoods are much more widely known. For the sake of clarity, I will refer to the set of disadvantages whose presence is directly related to the proportion black within a neighborhood as Directly-Related Disadvantages (DRD) and the set of disadvantages whose presence is inversely-related to the proportion black within a neighborhood as Inversely-Related Disadvantages (IRD).

\section{Directly-related Disadvantages}

Massey (1990) explained the link between segregation and racial inequality, illustrating how "an increase in poverty concentration radically transforms the 
social and economic environment." Massey uses the initial racial disparities created by slavery, Jim Crow, and redlining as a starting point from which the "intensification of poverty" occurs to a much greater extent in segregated black communities during times of economic dislocation.

To illuminate how changes in the American economy of the 1970s adversely affected blacks much more than whites, Massey starts by constructing an artificial city with a black poverty rate of 20 percent and a white poverty rate of 10 percent, numbers that were reasonably reflective of inner cities at the time. In a completely integrated city, everyone lives in neighborhoods with an equal poverty rate, whereas in a completely racially segregated city, the city's black population is subjected to a much higher poverty rate than the city's white population. Massey also adds an element of class segregation to the racial segregation and shows how impoverished blacks under such a condition can live in neighborhoods with disproportionately higher poverty rates relative to the rest of the city. Under these conditions, the impact of economic shifts varies widely by race and class, with poverty rates substantially increasing in some of the neighborhoods and having little effect on other neighborhoods. This is precisely what happened as manufacturing jobs declined, the service sector grew, and opportunities moved to the suburbs after the post-WWII economic boom faded in the 1970s. Massey's explanation here directly suggests that the adverse effects of racial segregation are directly related to the black proportion within a neighborhood, rather than effects only occurring in a neighborhood that is at least a particular percentage black.

Massey looks at census tracts and regresses several characteristics over the poverty rate and percent white, concluding that neighborhoods with increasing poverty rates experienced significant decreases in net buying power as the result of decreased average incomes. Consequently, the quality of housing deteriorated, and the social composition of neighborhoods shifted as the number of families in public assistance programs increased. Already-impoverished neighborhoods also experienced increases in crime and violence during the 1970s, which consistently 
correlates with increased mortality. In such neighborhoods, standardized test scores are lower, and dropout rates are higher. This confluence of factors creates an extremely disadvantageous environment for growing up, seeking work, and living healthily.

Massey (1995) expands on his earlier article to focus specifically on the rising rate of black violent crime during the 1980s to early 1990s, positing that poverty and segregation "interact to create a unique ecological niche for blacks, within which violent behavior becomes a logical, rational adaptation." One of his central observations is that poor black families are much more likely than poor white families to be surrounded by other poor families. This is broadly applicable to many measures related to segregation and is critical to understanding the causes and consequences of generational poverty. The life course for those growing up neighborhoods of the persistently impoverished is shaped by a "street orientation"one tending to focus on local, interpersonal conflicts over limited opportunities and resources. Adopting violent behavior-often at a collective level through fictive kinships such as gangs-helps maintain one's status within this harsh environment, while perpetuating the root problem by driving away anyone with the economic means to relocate. Reducing crime, then, requires not merely fighting the psychosocial symptoms of generational poverty, but addressing segregation head-on.

An early study of the Gautreaux experiment, where predominately black individuals residing in a predominately black inner-city neighborhood were moved to a predominately white suburb, found that mothers who had moved to the predominantly white suburbs had higher rates of employment compared to those who had stayed in the city. (Popkin et al. 1993) Gautreaux children that had moved to the suburbs were also more likely to graduate from high school and more likely to attend college as well as to be employed and have jobs with higher pay and benefits. (Rosenbaum 1992) Boys who moved to the suburbs were further much less likely to be involved in the criminal justice system. (Keels 2008) Fifteen years after the program began, after which some of the female participants had moved from the 
predominately white suburbs, or not, the racial composition of women's neighborhoods still had an effect on women's employment, earnings, and likelihood of being a welfare recipient, with lower chances of employment, lower chances of earning, and higher chances of being a welfare recipient. (Keels et al. 2005, Mendenhall et al. 2006)

Similarly, the Moving to Opportunity Housing Experiment was a housing experiment conducted by the Department of Housing and Urban Development, beginning in the 1990s and consisted of over 4,600 families. Families were randomly assigned to three different groups, with one group being assigned housing vouchers that could only be used in low-poverty areas. Chetty et al.'s (2016) analysis of the experiment found that moving to a lower-poverty area before the age of 13 increases college attendance rates and income levels while decreasing rates of single parenthood. Moving to a lower-poverty area after the age of 13 was found to have a slightly negative effect, attributed to disruption.

\section{Disadvantages as Disincentives}

Krysan and Farley's (2002) research, while determining factors that drive blacks to prefer neighborhoods with larger black proportions, also determined factors that counter that effect by driving individual's to prefer neighborhoods with lower black proportions. Only $2 \%$ (or 44 subjects) of respondents said their first preference for neighborhood racial composition would be all-white, but of those who did, 50\% attributed their choice to better neighborhood characteristics, including "better public services," "better quality of goods", as well as "the crime rate would be lower". Of the $5 \%$ of individuals whose first preference was "almost all white with a couple black families," $30 \%$ of that group as well attributed their choice to those same "better neighborhood characteristics."

Stipak and Hensler (1983) argue that economic disadvantages, rather than racial prejudices, bear primary responsibility for the aversion to black 
neighborhoods on the part of both black and white homebuyers. In the first part of their study, the authors analyze a broad set of survey data in multiple US cities to determine that, on average, preferences relating to "(1) safety for the respondent, (2) available recreational facilities, (3) quality of the local public schools, and (4) an overall evaluation of the neighborhood as a place to live" predict roughly 65 percent of neighborhood home-buying decisions. The preferences of white and black respondents were nearly the same when adjusting for income level. Stipak and Hensler assert this indicates that "the important explanatory is not the broad sociological concept of class, but simply the level of poverty, as measured by income." The social problems caused by widespread poverty are, in other words, equally unappealing to blacks and whites alike. However, given their lower average income, black homebuyers cannot as often afford to satisfy their neighborhood preferences as effortlessly as whites, and therefore are more likely to end up in more impoverished, higher black proportion neighborhoods.

Pfieffer's (2012) research on African-Americans who moved from inner-city Los Angeles to exurban areas agreed with the preferences outlined, finding the high levels of inner-city crime to be a primary factor in African-American's residential move, as well as to a lesser extent interest in higher-quality schools. Ultimately, racial segregation, the abundance of black proportion within a neighborhood, is correlated with a variety of disadvantaging neighborhood qualities, including higher poverty rates, higher crime rates, lower quality of public services, and lower quality of infrastructure. Outcomes correlated with residences in a predominately black neighborhood include increased risk of mortality, unemployment, poverty, dropping out of high school, and becoming incarcerated. The extent to which blacks let these risks and factors impact their neighborhood preferences is not fully understood, but as demonstrated by Krysan and Farley's (2002) findings, Stipak and Hensler's (1983) research, as well as Pfieffer's finding of African-Americans moving out of inner-city areas to avoid crime rates, many of these factors do significantly impact residential preferences and choices. 


\section{Inversely-Related Disadvantages}

White Americans and other non-blacks, in general, are the primary perpetrators of anti-black discrimination. English et al. (2014) assessed experienced racial discrimination using the six items from the Discrimination Scale of the Experience of Discrimination Questionnaire finding that the percentage white in a neighborhood is positively correlated with experienced racial discrimination for black residents at a highly significant level (<.001). They also found that experienced racial discrimination is heavily correlated with depressive symptoms leading to an insignificant indirect effect between neighborhood racial composition and depressive symptoms. Lyons (2008) looked at anti-black hate crimes reported to the Chicago Police Department. Hate crimes are typically more extreme manifestations of overt racism; less extreme incidents that should be considered hate crimes often go unreported. Regardless, Lyon's data found a statistically significant direct correlation between the percent white in a neighborhood and the number of anti-black hate crimes.

In terms of the Gautreaux experiment, as I discussed earlier, some research found evidence of disadvantages facing the blacks residing in the predominately white suburb. Those who had moved to the predominately white suburb reported significantly more racism compared to those who stayed in the black inner-city, with $52 \%$ of those who moved reporting experiencing racial discrimination in the first year compared to only $23 \%$ for those who stayed. (Rosenbaum 1991) An anecdote from a study on the Gautreaux Experiment offers support for the reduced presence of racial discrimination in predominately black neighborhoods, as one adolescent black girl reported having only seen white people on television before relocating to a predominately white neighborhood. (Popkin et al. 2010) Her statement attests to the starkness of racially segregated neighborhoods, as individuals in these neighborhoods can go long periods without encountering non- 
black people, and subsequently avoid the potential discrimination and hostility that blacks may be subject to through interracial interactions.

Agan and Starr (2017) found employer's neighborhood racial composition to play a role in the extent of employer's racial discrimination, experimenting with sending job applications of equal quality with white-sounding and black-sounding names to low-skills job postings. They found generally speaking that white applicants were $23 \%$ more likely to get a callback than black applicants, however, they found employers in black neighborhoods tended to discriminate against blacks to a much less extent than employers in less black neighborhoods, a statistically significant inverse correlation between neighborhood black proportion and the black-white job callback ratio. In neighborhoods that were over 50\% black, black applicants ended up with a slightly higher overall callback rate than white applicants. (though not a statistically significant difference)

The racial composition of a community tends to predict the racial composition of the community's police force. Donohue and Levitt's (2001) research found that police forces that increased the number of white police officers on their force significantly increased the number of non-white arrests while having little effect on the number of white arrests. Conversely, police forces that increased the number of non-white police officers had an increase in the number of white arrests, while having little effect on the number of non-white arrests. Since increases in the number of white police officers are intuitively more likely to happen in an area with more white residents, and increases in the number of non-white officers are intuitively more likely to happen in an area with more non-white residents, this suggests there may be yet another advantage to non-whites in living in areas with higher numbers of non-whites.

Postmes and Branscombe (2002) examined the impacts of segregated life contexts on Blacks. The racial composition of their life context was assessed on the composite basis of "percentages for the neighborhood they grew up in, the high school they attended, and their current friends" The black proportion within a 
blacks past and present life contexts were found to be inversely correlated with ingroup rejection and directly correlated with out-group rejection. Postmes and Branscombe also found a direct correlation between out-group rejection and selfcategorization and social identification as an African-American, and conversely an inverse correlation between in-group rejection and self-categorization and social identification as an African-American. Self-categorization was, in turn, directly correlated with higher collective self-esteem, while social identification was directly correlated with higher collective self-esteem and life satisfaction. The series of correlations produced an indirect effect between black proportion in the past and present life contexts and collective self-esteem in blacks.

Similarly, Hurd et al. 's (2013) research found that neighborhood racial composition had a significant moderating effect on how private and public regard affected black teenager's psychological well-being. In neighborhoods with lower numbers of black residents, private regard had a much more negative impact on depressive symptoms, as having a very low private regard in a non-black neighborhood was linked with a higher number of depressive symptoms than the equivalent private regard for an individual in a black neighborhood. Distinctly, neighborhood compositions had opposite mediation on the effect of public regard on depressive symptoms. Public regard was directly correlated with depressive symptoms in predominantly non-black neighborhoods but inversely correlated with depressive symptoms in predominantly black neighborhoods. Vogt-Yuan (2007) examines the emotional well-being of Blacks as it relates to the racial composition of their neighborhood, finding that black resident's emotional well-being is positively related to the proportion black within their neighborhood and that this relationship is partially explained by the correlation between neighborhood proportion black and the level of social support subjects reported.

Landrine's and Klonoff's (2004) operant theory of acculturation posits that acculturation's effects on health behaviors are dependent on the prevalence of the health behaviors in the traditional ethnic population. Alcohol use tends to be higher 
among white Americans than Blacks. Klonoff and Landrine (1999) found that more African-American acculturation is correlated with the abstinence of consuming alcohol. By contrast, African-Americans that were most acculturated to mainstream Eurocentric culture had the lowest rates of alcohol abstinence. Clark and Nguyen (2012) also found that adolescents that are more acculturated are more likely to use alcohol and other substances. Stock et al. (2013) found black racial identity to be uniquely associated with several detrimental tendencies, such as positive images of substance users and increased willingness to use substances, but only in predominately white environments.

Goosby and Walsemann (2012) found that black adults who had attended predominantly white schools tended to rate their health more poorly as adults than black adults who had attended schools with more non-white students which the authors attributed to aa number of negative attributes of predominantly white academic settings. Racial discrimination has been found to negatively affect youth development and adult health, a phenomenon which tends to happen more in predominantly white environments. Goosby and Walsemann (2012) further propose "important social integration and support mechanisms for explaining the influence of school racial composition on race/ethnic differences in early adult health." Social support and racial socialization serve as two critical means by which black adolescents are buffered from stressors. Racial identity serves as another possible explanation for health outcome variation, as an individual is less negatively impacted by discrimination or hatred if they have a more positive attachment to their identity. In predominantly white settings, there are fewer sources of reinforcement to black adolescent's identity.

Support networks within the black community contribute significantly to the coping and resilience of blacks. When blacks tend to encounter stress in their life, they tend to utilize support from group or kin networks. (Daly, Jennings, Beckett, and Leashore 1995) "Leaning on shoulders" refers to blacks' coping with the stress of predominately white society through social support from other blacks. (Shorter- 
Gooden 2004) In All Our Kin (1975) Carol B. Stack described the techniques and practices by which blacks and families utilize extended kinship and other social networks to survive. "Swapping" is a practice by which mutual aid is freely transferred within social networks, aiding individuals during different times of need. "Child-keeping" can involve multiple individuals accepting responsibility to help care for a child, thus lessening the burden of a single particular parent, allowing them to better deal with other challenges they face, and allow them to maintain occupational obligations better. These networks ultimately contribute to black survival. Importantly, these networks tend to almost exclusively involve blacks and operate within the confines of predominately black areas.

Fictive Kinship is a vital resource of informal social support for blacks and is very prevalent within the modern black community. Conversely, there are very few examples of fictive kinships in white communities, with the notable exceptions of fraternities, space often unwelcoming of black membership. Anderson (1978) looked at the fictive kinships present of a small social group of men in a predominately black neighborhood. He found that for these men, the relationships within the group, though not family, served as these individuals' most significant source of psychological and social support. The fictive kinships he analyzed served important roles of support within one another's lives, helping each other through poverty, medical issues, and death. Anderson further found that fictive kinships, helped individuals to establish a personal and group identity. Liebow (1967) examined fictive kinship relationships among black men, finding that individuals' fictive kinships tended to be with individuals who also resided in the very same immediate area, spending much of their time within the same neighborhood.

To quote Grayman-Simpson and Mattis (2013), “The helping tradition within the African American community is uniquely characterized by a combined focus on dedicated time, skills, and financial resources toward activities aimed at dismantling obstacles to Black progress and empowering individual and families" Patillo-Mccoy (1998) examined the effectiveness and ability of black church 
community in addressing black community needs. Patillo-Mccoy that the church culture and organization served as a uniting community site with which individuals who shared common black community interests to come together to work on solutions to their common problems. Black church culture served as the leading agency in addressing many community needs such as curbing youth delinquency, closing a neighborhood drug house, and attracting voters. In communities with low black populations, it is easy to see how black community members may not have the organization, capability, or simple numbers to unite to lead community change in their interest.

Terhune's (2008) examination of black women's' experience living in a predominately white region reveals isolation as a common challenge faced. Black women living in this region were noted as not merely being isolated as a result of a lack of a significant black population but as a result of being unable to connect with the native black population as a result of their status as being new to the area. Many of the women eventually formed social support networks with other black "transplants" to the region, to cope with the social and cultural isolation they face in their community. Other consequences of isolation were the women's tendency to return to their hometown, their original support network, often.

\section{Disadvantages as Disincentives}

Evidence suggests that many of the disadvantages blacks face from residing in predominately white neighborhoods that I have introduced earlier have a significant impact on black neighborhood preference. Krysan and Farley's (2002) research concluded as other research has that blacks' ideal neighborhood racial composition preference is about $50 \%$ white $50 \%$ black, as $50 \%$ of their sample selected that as their first preference among five different neighborhood racial composition options. Results of blacks' reasoning for their preferences supports several notions that several disadvantages associated with predominately white 
neighborhoods do heavily influence black neighborhood preferences. For instance, in support of discrimination as an influencing factor, $15 \%$ of the $23 \%$ of blacks who said their first choice for neighborhood composition would be an all-black neighborhood attributed their choice to "a desire to avoid whites because of the hostility they would feel." Preference for living with blacks out of comfort and the feeling that "it's my own kind" accounted for 50\% of black's attribution to the preference for living in an all-black neighborhood. Another $7 \%$ of these blacks attributed their preference to valuing cultural similarity with neighbors.

Krysan and Farley (2002) also found individual perceptions of discrimination to impact why different people selected different neighborhoods. For instance, blacks who said there was "some" or "a lot" of discrimination against blacks in the job market were statistically unlikely to select the mixed, mostly-white, or all-white neighborhood as their first choice. Similarly, blacks who said that "blacks were easier to get along with than whites" or there was "no difference" were statistically more likely to select a neighborhood preference of at least $50 \%$ black. This sentiment is vague but again alludes to the impact of interracial interactions that plague black people through the presence of discrimination, hate, and microaggressions.

Discrimination and hate crimes seem to be inversely correlated with the black proportion within neighborhoods. Although not directly correlated with neighborhood racial composition, significant evidence has linked instances of discrimination with a variety of adverse outcomes, in terms of mental health and physical health outcomes. Black proportion within neighborhoods are also related to employment discrimination, and black proportion on police forces relate to black arrests. Other literature has linked black proportion with differential outcomes in terms of racial identity and in-group acceptance, which have, in turn, negatively affected self-esteem, mental health, and depressive symptoms. Krysan and Farley's (2002) research shed light on how many disadvantages impact black neighborhood 
preferences, supporting evidence that discrimination, in-group preference, and cultural similarities all profoundly impact blacks' neighborhood preferences.

\section{Implications of Disadvantages}

As I have outlined, there is considerable evidence to suggest certain disadvantages pertaining to blacks tend to have more considerable significance in predominately non-black environments, while other black problems have more considerable significance in predominantly black environments. Evidence is limited but many of these disadvantages likely and for a good reason disincentivize black choices. Salient challenges are more likely to affect decision-making. In predominantly black neighborhoods, crime seems to be one of the stronger disincentives to blacks' residential choice. Crime in itself, however, may not be the problem in black neighborhoods with the most substantial negative effect, but is associated with other problems, such as high poverty rates and lowerperforming public schools.

Discrimination or more vaguely "white hostility" in various forms seems to be a strong disincentive to blacks from residing in white neighborhoods. This notion is supported by individuals' stated reasoning for preferring to live in black neighborhoods. Discrimination in various forms is also likely one of the most significant issues facing blacks in white communities. There is less clear evidence regarding the extent to which other disadvantages associated with white spaces were related to influencing residential, educational, or employment choices. Krysan and Farley's (2002) research also suggested a desire for "cultural similarity" and to be with one's kind are significant factors in driving black neighborhood preferences away from white neighborhoods. Disincentives are not perfectly correlated with disadvantages, but there certainly is a strong relationship. 
The direct consequences of two inversely related sets of disadvantage are apparent. Blacks, generally speaking, face a disadvantage in whatever racially composed neighborhood they live in the United States. Beyond that, they are torn to live in these distinct places as a result of significant disincentives, pulling them towards a location where they ultimately will be met with a significant challenge/disadvantage as well. The significance of this occurs only as a result of segregation producing different types of communities with varying levels of black proportion. Inversely related sets of disadvantages fit together to form a complete series of options wherein blacks face significant disadvantage in whatever racial composition of neighborhood in which they reside. As a result of this, there is no right choice for black residential preferences, because each choice based on racial composition has some combination of significant disadvantages associated with it. Both of these inversely related sets of disadvantages uphold this system because in the absence of either set of disadvantages, blacks would be significantly better off as they would have a more advantageous choice. The existence of both forms of disadvantage coupled with two forms of disadvantage affecting the perceived utility of either type of neighborhood, for which I would like to emphasize the distinction of as perceptions of disadvantages rather than the actual disadvantages themselves, leads to both types of disadvantage reinforcing the effects of the other. I call this the Black Proportion Paradox.

Choosing what community to reside in is not simple, and most households maintain residence in their current community rather than move to a new one. (Sampson and Sharkey 2008) Further, there are many challenges blacks have and continue to face in accessing new communities. Krysan and Farley (2002) found that among the $23 \%$ of blacks that would prefer to live in an all-black neighborhood, $10 \%$ attributed their preference to that it is "what (they have always been) used to." A growing black middle-class however suggests that a larger and larger portion of black communities can afford to live in the more affluent communities that predominately white neighborhoods tend to be. There, of course, are several other 
barriers to blacks' accessibility to residence in white communities. Changing communities is not easy, but as recent historical evidence has demonstrated, given significant push and pull factors, massive population migrations between racially composed neighborhoods can be influenced to occur.

I have until now solely addressed directly-related disadvantages effect on residential choices as merely being a disincentive, but the picture is significantly more convoluted. As I earlier suggested, directly-related disadvantages are rooted in neighborhood levels of poverty and income. The phenomena of predominately black neighborhoods having higher poverty rates and lower median incomes are for the most part logically contingent on blacks having higher poverty rates and lower median incomes compared to whites and other racial groups in general. So the existence of directly-related disadvantages is contingent on black's lower median income effectively limiting the extent to which blacks can reside in predominately non-black areas as they are less likely to be able to afford them. This limitation again stands in distinction to the notion that blacks are likely to have a higher preference for predominately non-black neighborhoods when directly-related disadvantages are higher, as it instead suggests that blacks are less likely to be able to afford to choose to live in a predominately non-black neighborhood when directlyrelated disadvantages are higher. On top of this effect, it is also important to note that evidence strongly suggests whites are likely to be more averse to higher percentages of black residents in a neighborhood when directly-related disadvantages are more significant. (Bruch 2014). Ultimately these two mechanisms in accord produce the effect that directly-related disadvantages, proxied as "between-group inequality" actually tends to be directly related to the percentage of residents that are black in the average black's neighborhood. (Bruch 2014) However, this relationship does not apply equally to black subpopulations. Bruch's (2014) models suggest that while the neighborhood black proportion of poor black resident's tends to be directly related to between-race inequality while 
affluent black resident's black neighborhood proportion tends towards an inverserelation with between race-inequality.

Between-Race Inequality can serve as a proxy for Directly-Related Disadvantages. Massey (1990) argued that the level of income and poverty within a neighborhood was the causal factor behind neighborhood disadvantage, as levels of poverty rose and income dropped within a neighborhood, many differential outcomes were observed, including increasing crime rates and falling graduation rates. Racial segregation and concentrated disadvantage, which tends to be measured by levels of income and rates of poverty are closely related. Sampson et al. (2008) for example, measures concentrated disadvantage as "welfare receipt, poverty, unemployment, female-headed households, racial composition (percentage black), and density of children."

\section{Rational-Choice Implications}


Based on the ideas brought forth, I can construct an arbitrary utility function for a black perspective neighborhood preference based on the disadvantages I have discussed already

$$
U_{i}=U_{\text {Max }}-a_{1}\left(p_{i}\right)-a_{2}\left(1-p_{i}\right)+\epsilon
$$

such that $a_{1} \geq 0$ and $a_{2} \geq 0$

$U_{\text {Max }}$ is the utility that a neighborhood possesses if it has no disadvantages. Since a neighborhood that has no disadvantages is the most appealing, this utility is the highest that a neighborhood could have, thus why I call it the maximum utility. $a_{1}$ represents the quantified effect of disadvantages whose presence are directly correlated with the black proportion and $a_{2}$ represents the quantified effect of disadvantages whose presence are inversely correlated with the black proportion. $p$ denotes the percent of residents that are black within a neighborhood. $€$ refers to unobservable factors that contribute to the utility.

A logit model of neighborhood choice (assuming that the epsilons are i.i.d. across the alternatives and have type 1 extreme value distributions) produces the following probability that an individual choices a particular neighborhood $i$ among $n$ choices:

$$
\operatorname{Pr}(\mathrm{i})=\frac{e^{\left(U_{i}\right)}}{\sum_{\mathrm{k}=1}^{n} e^{U_{k}}}
$$

or

$$
\operatorname{Pr}(\mathrm{i})=\frac{e^{\left(U_{\operatorname{Max}}-a_{1}\left(p_{i}\right)-a_{n}\left(1-p_{i}\right)\right)}}{\sum_{k=1}^{n} e^{U_{k}}}
$$

Based on a logit model of neighborhood choice, the expected utility of a black's choice of neighborhood based on my preference model can be written as a function of the mean neighborhood utility:

$$
\sum_{1}^{n} \operatorname{Pr}(\mathrm{k}) U_{k}=\mathrm{U}_{\text {mean }}+\sum_{\mathrm{k}=1}^{n} \frac{\left(\left(\left(U_{\text {mean }}\right)-U_{k}\right) e^{\left(U_{k}\right)}\right)}{\sum_{\mathrm{k}=1}^{n}\left(e^{\left(U_{k}\right)}\right)}
$$


I define the mean neighborhood utility as:

$$
U_{\text {mean }}=\frac{\sum_{1}^{n} U_{k}}{n}
$$

Let $a_{1}+a_{2}=a_{\text {Total }}$ where $a_{\text {Total }}$ is a constant and assume there exists a symmetric distribution of black proportions across neighborhoods That is, if $x$ neighborhoods with black proportion $p=y$ exist, then $x$ neighborhoods with black proportion $p=(1-y)$ exist, as well. (I choose to utilize a symmetric distribution of black proportions across neighborhoods because non-symmetric outcomes may unintentionally and distractingly imply differences in the dynamics of either set of disadvantages as I have described them, while the underlying phenomena I seek to demonstrate with this example is present instead under any given distribution of proportions)

The minimum possible average utility of black neighborhood choices is $U_{\text {mean }}$ and occurs when $a_{1}=a_{2}$ where every neighborhood faces an equivalent extent of disadvantage and a subsequent equivalent utility. Clearly, at this point too, the maximum expected utility a black can choose, is at a minimum.

The maximum possible average utility of black neighborhood choices occurs when $a_{1}=0$ and $a_{2}=a_{\text {Total }}$ or when $a_{2}=0$ and $a_{1}=a_{\text {Total }}$

Removing the prior condition of $a_{1}+a_{2}=a_{\text {Total }}$ two other clear conclusions of the logit models are that holding $a_{1}$ constant, an increase in $a_{2}$ subjects the average black to greater impact from $a_{1}$ and conversely, still holding $a_{1}$ constant, a decrease in $a_{2}$ subjects the average black to greater impact from $a_{1}$

These findings relate to the significance of black's facing two sets of disadvantage that are inversely related to the proportion black of residential neighborhoods. As a result of the two types of disadvantage being inversely related, the variance of utilities across neighborhood options is reduced, which minimizes the potential collective utility enacted through differential choice-making, subsequently causing the manifestations of disadvantages to be stronger. Further, 
the simultaneous presence of both forms of disadvantage is significantly worse than the combined effects of both forms of disadvantage individually.

If only a single set of advantage/disadvantage existed, the black population would be immensely better off. If disadvantages associated with white neighborhoods and sites disappeared and no longer existed, blacks already living and interacting in white spaces would be better off, but some individuals who had previously lived in and interacted in black spaces would become better off as the black population shifted to whiter neighborhoods and sites and these blacks no longer had to deal with the problems associated with black neighborhoods and sites while subsequently being able to avoid the no longer existent disadvantages of white neighborhoods. Conversely, the same is true if disadvantages associated and correlated with black neighborhoods and sites disappeared and no longer existed, blacks already living and interacting in black spaces would be better off, but some individuals who had previously lived in and interacted in white spaces would be better off as a significant portion of the black population shifted to blacker neighborhoods and sites, and these blacks no longer had to deal with the problems associated with white neighborhoods while subsequently being able to avoid the no longer existent disadvantages of black neighborhoods. This generalized scenario is heavily contrived, but it nonetheless gets across the point that either single set of disadvantages plays a role in upholding the inversely related set of disadvantages.

\section{Static Demonstration:}

Consider four static scenarios: a scenario in which there is no disadvantage directly correlated with the black proportion within a neighborhood as well as no disadvantage inversely correlated, a scenario in which there is a disadvantage directly correlated with the black proportion within a neighborhood but no disadvantage inversely correlated, a scenario in which there is a disadvantage inversely correlated with the black proportion within a neighborhood but no 
disadvantage directly correlated, and finally a scenario in which there are high disadvantages both directly and inversely correlated with the black proportion within a neighborhood.

For simplicity's sake, let the maximum utility a neighborhood can have be 10 , and a coefficient of 5 represents the negative effect of either type of disadvantage For all the Scenarios I will apply the Neighborhood Utility distributions to 5 neighborhoods of varying black proportions $(0 \%, 25 \%, 50 \%, 75 \%, 100 \%)$

The probability (equivalent to the percent of the black population that makes that choice) that a black resident chooses a particular neighborhood will be modeled based on the probability functions mentioned above.

\section{Scenario One:}

$$
U_{i}=10-5\left(p_{i}\right)-0\left(1-p_{i}\right)+\epsilon
$$

Or

$$
U_{i}=10-5\left(p_{i}\right)+\epsilon
$$

The average utility of a neighborhood is 10 , and the average utility of a black neighborhood choice in this scenario is 10. (See Table One)

\section{Scenario Two:}

$$
U_{i}=10-5\left(p_{i}\right)-0\left(1-p_{i}\right)+\epsilon
$$

Or

$$
U_{i}=10-5\left(p_{i}\right)+\epsilon
$$

The average utility of a neighborhood is 7.5 , and the average utility of a black neighborhood choice in this scenario is 9.510. (See Table Two) 
Scenario Three:

$$
U_{i}=10-0\left(p_{i}\right)-5\left(1-p_{i}\right)+\epsilon
$$

Or

$$
U_{i}=10-5\left(1-p_{i}\right)+\epsilon
$$

The average utility of a neighborhood is 7.5, and the average utility of a black neighborhood choice in this scenario is 9.510. (See Table Three)

Scenario Four:

$$
U_{i}=10-5\left(p_{i}\right)-5\left(1-p_{i}\right)+\epsilon
$$

Or

$$
U_{i}=5+\epsilon
$$

The average utility of a neighborhood is 5 , and the average utility of a black neighborhood choice in this scenario is 5. (See Table Four)

My four scenarios demonstrate the possible effects of the Black Proportion Paradox. Scenario One features no neighborhood disadvantages in any neighborhoods. Thus all neighborhoods in that scenario have a utility of 10 , and the average utility of a black neighborhood choice is also 10. Scenario Two and Three produce an equal average neighborhood choice utility for black residents of 9.510, only slightly lower than the 10 in Scenario One, despite the average utility of neighborhood options in Scenario Two and Three of 7.5. In Scenario Two, the average black proportion of a black resident's neighborhood is low, as neighborhood utility is inversely correlated with black proportion, and thus black residents are pulled towards neighborhoods with lower black proportions. Conversely, in Scenario Three, the average black proportion of a black resident's neighborhood is high, as neighborhood utility is directly correlated with black proportion, and thus black residents are pulled towards neighborhoods with higher black proportions. 
Scenario Four demonstrates the dangerous disproportionate effect of the Black Proportion Paradox. Whereas the average neighborhood utility in Scenario Four is 5, only 2.5 lower than Scenario Two and Three, the average neighborhood utility of a black resident's choice in Scenario Four is 5, 4.51 lower than Scenario Two and Three, a disproportionate gap. In Scenario Four, the neighborhood disadvantages from Scenario One and the neighborhood disadvantages from Scenario Two are simultaneously present so that there are inversely-related neighborhood disadvantages. Whereas the range of Neighborhood Utility varied from 5-10 in Scenario Two and Three, there is no variation in Neighborhood Utility in Scenario Four. All neighborhoods have a utility of 5. Furthermore compared to both Scenario Two and Three, black residents in Scenario Four are subject to higher levels of both disadvantages directly related to black proportion and disadvantages inversely related to black proportion, as the average black resident in Scenario Two and Three only had .49 of their neighborhood utility affected by one of the two types of disadvantages and was not affected at all by the other, in Scenario Four the average black resident has their neighborhood utility lowered by 2.5 by one form of disadvantage as well as 2.5 by the other form of disadvantage.

\section{Empirically-Grounded Simulations}

To both test the notion of whether or not black residential preferences vary as a result of the described disadvantages as well as examine broader implications of those preferences, I performed Interactive Markov Models following the methods described in Bruch and Mare (2006). I obtained data on black residential preferences from the Multi-City Study of Urban Inequality. Data from this study had the advantage that it not only contained subjects' residential preferences from vignette questions but also contained data on subjects' perceptions of racial groups based on various characteristics. From this, I can estimate black residential preferences under different conditions of disadvantage. I only include blacks from the study that resided in black neighborhoods. I proxied subjects' perceptions of 
Directly-Related Disadvantages based on the difference between the extent to which subjects' perceived blacks to be associated with drugs and gangs relative to whites. Given crime as a central attribute of what blacks view as unfavorable about residence in black neighborhoods (Pfeiffer 2012), I felt this was an appropriate proxy. I proxied subjects' perceptions of Inversely-Related Disadvantages based on the extent to which subjects' perceived white's treat others discriminately. (For specific wording of questions, see appendix) In general, I must emphasize that this simulation of blacks' behavior is not based on varying conditions of disadvantages directly, but varying conditions of perceptions of disadvantages.

Based on this proxies, I created four sub-groups of black subjects to represent various conditions of disadvantage. The four conditions are Low-IRD/Low-DRD, High-IRD/Low-DRD, Low-IRD/High-DRD, and High-IRD/High-DRD. I group all subjects into one of the four groups based on whether or not their proxy values fall above or below the median score for a given proxy. (Any subjects' score that is equivalent to the median is grouped into whatever category had fewer subjects) I then calculate ranked order logit models for each of the four unique subgroups. Similar to the methodology of Bruch and Mare (2006), I use interactive Markov models to simulate residential patterns over time, starting with a collection of "neighborhoods" such that initially blacks and whites are completely segregated. In every step, I allow a unique proportion of blacks to choose a new neighborhood based on the preferences as governed by particular conditions. I do not give whites the option to change neighborhoods at any point in the simulation. I do this because whites' residential preferences tend to be so heavily skewed they almost always choose to remain in the whiter neighborhood, even as segregation falls significantly. I allow the Interactive Markov Models to run for 20 steps.

Across the four conditions, I allow two parameters to vary. I allow the proportion of the black population that can choose their residence to vary. I do this to simulate the effect of within-race inequality, a population characteristic that has a significant effect on how segregation manifests, as identified by Bruch (2014). 
Even under conditions of high between-race inequality, poor blacks tend to remain in black neighborhoods. Affluent blacks, on another hand, are much more likely to choose to reside in a broader range of neighborhoods. As within-race inequality increases, the proportion of blacks that are affluent increases, and thus so does the proportion of blacks that are going to exercise agency in achieving their residential preferences. Further, in most large metropolitan areas, there usually exists one or more virtually all-black neighborhoods.

The second parameter I allow to vary is the proportion of the population within the simulation that is black. Since my Interactive Markov Models operate without restriction on the number of agents that can choose a particular neighborhood, I choose to vary the proportion of the population that is black, via manipulating the number of initial equally-sized white 'neighborhoods' relative to exactly one black 'neighborhood' in each simulation.

\section{Results}

The logit preference equations for the four groups as computed based on the preferences are listed in Table Five.

Tables Six, Seven, and Eight show how our utility models would predict blacks to choose in each of three pairs of black neighborhoods. Across all four simulations, we see blacks tend to choose the neighborhoods with lower black proportions at higher rates when Directly-Related Disadvantages are high compared to when they are low. The difference in preferences between when Inversely-Related Disadvantages are high and are low is more nuanced, however. Inversely-Related Disadvantages appear to matter more when deciding between neighborhoods with higher black proportions as well as when Directly-Related Disadvantages are low.

A more careful examination reveals that when Directly-Related

Disadvantages are high, the only real effect of Inversely-Related Disadvantages is 
somewhat small, and more importantly only in lowering the utility of neighborhoods that are specifically about half-black and to a small extent the utility of neighborhoods that are one-quarter black. When Directly-Related Disadvantages are low however, Inversely-Related Disadvantages has a sizable effect on how neighborhoods around $25 \%$ to $50 \%$ black are perceived.

These four utility categories each have four unique utilities for a neighborhood that is $100 \%$ black. Table Nine depicts what other neighborhood proportion black equals the same utility as a $100 \%$ black neighborhood with the common utility in parentheses. While not necessarily absolutely true, a lower percentage generally means that condition group has a relatively higher preference for neighborhoods with a higher white proportion/lower black proportion while a higher percentage generally means that condition group has a relatively higher preference for neighborhoods with a lower white proportion/higher black proportion. Since I maintain one neighborhood at 100\% black consistently through my simulations (and since black agents under all four conditions have similarly-shaped utility functions), this information tells us what black proportion another neighborhood would have to achieve in order for black agents to prefer that neighborhood to $100 \%$ black neighborhood.

For the most part, across the various simulations, my most general expectations hold, specifically black agents have the highest level of experienced neighborhood black proportion when IRD is high. (See Figures One through Five) While I would expect black agents to experience the lowest level of neighborhood black proportion when IRD is low, and DRD is high, through all the simulations there is virtually no difference between the high-DRD high-IRD condition and the high-DRD low-IRD condition. In the $50 \%$ black population simulation, I expected to see the most substantial evidence of a difference between High-DRD Low-IRD and High-DRD High-IRD, however even there there is very little difference, and for a logical reason. When the black population is very large, the proportion black in the white neighborhood(s) is very sensitive to the residential preferences of blacks. So in 
our 50\% black simulation, when more blacks choose the "white" neighborhood over the all-black neighborhood, the proportion black in the white neighborhood increases, as a result, mitigating some of the overall benefits of more people choosing that more "white" neighborhood. To be specific, when $100 \%$ of the black population has the option of choice, $75.66 \%$ of the black neighborhood choose the "white" neighborhood under the High-DRD Low-IRD condition, while $72.11 \%$ do so under the High-DRD High-IRD condition. While the more "white" neighborhood in the High-DRD High-IRD condition has a black proportion of $41.90 \%$, the more "white" neighborhood in the High-DRD Low-IRD condition has a black proportion of $43.07 \%$. This results in the difference in the black proportion experienced by black subjects in the High-DRD Low-IRD condition and High-DRD High-IRD condition being $1.17 \%$, despite $3.55 \%$ more of the black residents in the High-DRD Low-IRD condition choosing the "white" neighborhood. Ultimately, since neighborhoods that are close to only $50 \%$ black tend only to form when the black proportion is high, we can in general across all possible black population sizes expect Inversely-Related Disadvantages to have minimal effect on black residential preferences when Directly-Related Disadvantages are high. Distinctly, when Directly-Related Disadvantages are low, Inversely-Related Differences can have a somewhat substantial effect on the proportion black experienced by blacks, even across a variety of black population sizes.

More broadly, these simulations suggest a few implications regarding how my two sets of disadvantage affect residential patterns. While variations in the utility functions of the four black sub-groups suggests the residential preferences of the black populations reflects their willingness to avoid two sets of proportionrelated disadvantages, two factors that confound the ability of these preferences to be manifested into large-scale reflective outcomes is variation in the size of the black population as well as variation in the proportion of the black population that has the option to choose their neighborhood of residence. For instance, even under a condition of High IRD and Low DRD, when the black proportion is low, the 
experienced neighborhood proportion black of black agents will be very low, and the majority of black residents will reside in neighborhoods with extremely low black proportion despite that being the significantly worse utility option. Thus, low total black proportion limits the ability of black agents to respond to High IRD appropriately. Juxtapose, a low percentage of black agents that can choose their neighborhood limits the ability of black agents to appropriately respond to High DRD, since those who cannot choose are stuck in the all-black neighborhood, and those who can choose are significantly less likely to choose the "white" neighborhood than otherwise since fewer other black agents are available to make the same choice.

As it relates to my next section, these simulations suggest a hypothesis for how these disadvantages relate to real-world residential dynamics. While these simulations generally suggest High IRD increases the neighborhood black proportion experienced by black agents, this is only likely to occur when DRD is low. Otherwise, I anticipate IRD to make little difference in residential outcomes.

\section{American Community Survey Data Analysis}

\section{Methods}

Next, I will perform an empirical test in regards to how variations in Inversely-Related Disadvantages and Directly-Related Disadvantages affects black residential patterns. Data comes from two sources, American Community Survey 5year estimates and Google Trends data. Google Trends data is a unique source of "found" data that has become increasingly popular in recent years. Google Trends data allows me to proxy something that is otherwise somewhat hard to get data for, the extent of racism for a specific geographical area. Stephens-Davidowitz (2013) first pioneered a technique for obtaining the Google Trends-based measure. He demonstrated that this measure was significantly correlated with other methods for proxying an area's level of racism, and was almost certainly even more accurate 
than the other methods given the scale of Google Trends data relative to other available data sources. I closely follow his method for calculating the level of racism, based on the frequency of Google searches for the singular and plural tense of a specific racial epithet (it begins with an "n"). Also following his method, I control for the frequency of three other search terms which may confound the search term of interest. I use 2004 to 2009 as my time frame for obtaining Google Trends data. In calculating the average neighborhood proportion black experienced by different income groups of black households, I utilize 2005-2009 and 2012-2016 American Community Survey 5-year estimates. I choose these years because Google Trends data is only available starting in 2004, and the 2005-2009 estimates are the first 5-year estimates available after that. In terms of modeling segregation, I primarily follow the method of Bruch (2014) as much as I can in analyzing segregation. Slightly distinct from their method however, I utilize Designated Market Areas (DMA's) rather than metropolitan areas as the geographical area of analysis. I do this because Google Trends data is available at that scale and not at the metropolitan scale. From the American Community Survey data, I calculate the average proportion black neighborhood experienced by different income categories of black households. Neighborhoods are defined as census tracts. I utilize 5-year estimates to estimate DRD, which I proxy as Between-Race Inequality, or each DMA's white per capita income divided by black per capita income. (Bruch estimates Between-Race Inequality as White Median Household Income divided by Black Median Household Income, this data is of course not available at the DMAlevel however)

Following the method of Stephens-Davidowitz, I eliminate Alaska from the analysis. Following the method of Bruch (2014) as well as Jargowsky (1996), I eliminate all DMA's that have less than 10,000 black households in either of the estimates utilized. This selection results in 122 DMA's, which makes up about $87 \%$ of the United States population. In general, following the findings of Bruch, I have a specific interest only in the neighborhood proportion black experienced by affluent blacks. As Bruch hypothesized, affluent blacks have disproportionality more 
available neighborhood options accessible and appealing to them on average compared to poor blacks. This notion was confirmed in their findings when they found Between-Race Inequality to have a significant effect on the neighborhood proportion black experienced by affluent blacks, with little effect on that of poor blacks. Therefore, as a result of the underlying theoretical orientation, coupled with a lack of interest as elicited from empirical results, I will henceforth only focus my empirical analysis on affluent blacks. I define affluent black households as black households that have an income of over $\$ 100,000$.

In keeping with the precedent of Bruch (2014), I anticipate my two variables of primary-interest, Between-Race Inequality, and Racism, to have non-linear effects on the black proportion experienced by affluent blacks. Bruch's empirical analysis confirms the non-linear relationship between Between-Race Inequality and neighborhood proportion black experienced by affluent blacks and attributes this relationship to the need for a "critical mass" of black residents in order for neighborhood patterns to shift substantially. Further, based on my theoretical orientation and the findings of my Interactive Markov Models, I anticipate Racism and Between-Race Inequality to have an interaction between one another.

\section{Results}

My racism measure ranges from 20 to 80 , with the value representing a scale of the proportion of the DMA's total Google searches that include my racial epithet. Google Trends assigns the DMA with the highest proportion of Google Searches that include the racial epithet a value of "100" and assigns values to all other DMA's based on what that DMA's proportion is relative to the highest value. (E.g. a DMA with a value of 50 searches for the racial epithet at half the rate of a DMA with a value of 100 ; the DMA with the 100 value was eliminated from my selection as it did not have enough black households) The higher the value, the higher level of presumed "racism" in the DMA. (See Table Ten for Summary Statistics) 
I incorporate an interaction between quadratic terms of Racism and Inverse Between-Race Inequality into a basic model predicting the neighborhood proportion black experienced by black households with income over 100,000 in 2016 based on that number in 2009 as well as the change in the proportion black within the DMA. The nested F-value is 5.59, significant at the .001 level. While Bruch utilizes Between-Race Inequality in their models, I utilize the reciprocal of that in my model, so that the hypothesized effect of that term falls in the same direction as the hypothesized effect of racism.

The model (Table Eleven) more or less shows the core result as expected from the simulations. While the higher-order effects and interactions make it difficult to understand the effect of Racism and Between Race Inequality on proportion black experienced by affluent black, Figure Six visually depicts the relationship between racism and change in neighborhood proportion black at various levels of BetweenRace Inequality. An area's level of racism has a nonlinear, generally positive association between racism and change in the neighborhood proportion black experienced by affluent blacks, but only when Between-Race Inequality is low (Inverse Between Race Inequality is high), and the figure show the proportion black experienced by affluent black households increased the most in DMA's with high levels of racism and low levels of Between-Race Inequality. When Between-Race Inequality is high, an area's level of racism has virtually no effect.

Ultimately these results suggest implications for how combinations of disadvantages affect the residential situation of affluent black households. Under conditions of low-DRD, high-IRD makes a difference in increasing the neighborhood proportion black affluent blacks are exposed to, as a result of affluent blacks either moving to blacker neighborhoods or remaining in neighborhoods that become blacker. Distinctly, under conditions of high-DRD, the extent of IRD makes little difference in affecting the neighborhood black proportion experienced by affluent blacks. Considering the effects of the disadvantages directly, when DRD is low, and IRD is high, blacks will end up having greater exposure to DRD through increased 
exposure to neighborhood black proportion, while when DRD is high, the level of IRD is directly related to the level of IRD blacks are exposed to as their neighborhood black proportion experienced stays the same. While my initial discussion of Black Proportion Paradox suggested that the Black Proportion Paradox is a combination of Directly-Related and Inversely-Related Disadvantages that emerges as a result of the paradoxical influence of the disadvantages, my Interactive Markov Models as well as analysis of results suggest that the Black Proportion Paradox for Affluent Black residents is not so much a combination, but specifically rests in greater exposure to Inversely-Related Disadvantages when both Inversely-Related and Directly-Related Disadvantages are high as a result of little shift in the neighborhood proportion black experienced in response to this.

This paper, in general builds on the findings of Bruch (2014). Bruch found that Between-Race Inequality was a relevant attribute in determining the racial composition of affluent black's neighborhoods, via a fixed-effects model. While Bruch's work was focused on emphasizing the unique role of how income structure affects segregation, my work builds on her specific theoretical orientation and finding regarding affluent blacks by applying my framework for understanding disadvantages and specifically applying a new relevant variable, Inversely-Related Disadvantages, in predicting segregation. While income structure remains a critical attribute in determining not merely segregation patterns but also how blacks experience disadvantage, Inversely-Related Disadvantage critically serves as a companion mechanism both affecting behavior and experienced disadvantage.

\section{Conclusion:}

This paper suggests several significant implications for future thought on neighborhood qualities and how they relate to both which and how disadvantages affect black Americans as well as how segregation is experienced by black Americans. My theoretical orientation suggests the neighborhood disadvantages 
blacks are subject to are rooted in two inversely-related sets of disadvantage and that much of the significance of the disadvantage blacks are subject to is a result of this inverse relationship. My empirically-grounded simulations suggest that disadvantages that's presence tends to be inversely related to the black proportion within a neighborhood has a positive effect on the proportion black experienced by black residents, but only when Directly-Related Disadvantages, disadvantages that's presence tends to be directly related to the black proportion within a neighborhood, are low. My analysis of American Community Survey data supports this finding, as I find the level of racism with a Designated Metropolitan Area has a nonlinear positive association with the change in neighborhood black proportion experienced by affluent blacks between 2009 and 2016, but only when BetweenRace Inequality is low, otherwise there is little relationship. 


\section{References}

Agan, Amanda, Sonja Starr. 2017. 'Do Employers' Neighborhoods Predict Racial Discrimination?"

Anderson, Elijah. 1978. A Place on the Corner. Chicago: The University of Chicago Press.

Bobo, Lawrence, Johnson, James, Bluestone, Barry, Browne, Irene, Danziger, Sheldon, Moss, Philip, ... Twelly, Chris. Multi-City Study of Urban Inequality, 1992-1994: [Atlanta, Boston, Detroit, and Los Angeles]. Ann Arbor, MI: Interuniversity Consortium for Political and Social Research [distributor], 2008-04-23. https://doi.org/10.3886/ICPSR02535.v3

Booth, Alison L. and Leigh, Andrew and Varganova, Elena. 2009. "Does Racial and Ethnic Discrimination Vary Across Minority Groups? Evidence from a Field Experiment" Available at SSRN: https://ssrn.com/abstract=1521229 or http://dx.doi.org/10.2139/ssrn.1521229

Bruch, Elizabeth E. 2014. "How Population Structure Shapes Neighborhood Segregation." American Journal of Sociology 119, no. 5 1221-278. doi:10.1086/675411.

Bruch, Elizabeth E., and Robert D. Mare. 2006. "Neighborhood Choice and Neighborhood Change." American Journal of Sociology 112, no. 3 667-709. doi:10.1086/507856.

Chetty, Raj, Nathaniel Hendren, and Lawrence F. Katz. 2016. "The Effects of Exposure to Better Neighborhoods on Children: New Evidence from the Moving to Opportunity Experiment." American Economic Review, 106 (4): 855-902.

Clark, Trenette T., \& Anh B. Nguyen. 2012. "Family factors and mediators of substance use among African American adolescents.” Journal of Drug Issues, 42, 358-372. 
Clark, William A. V. 1992. "Residential Preferences and Residential Choices in a Multiethnic Context." Demography 29, no. 3 451-66.

http://www.jstor.org/stable/2061828.

Daly, Alfrieda, Jeanette Jennings, Joyce O. Beckett, and Bogart R. Leashore. 1995. "Effective Coping Strategies of African Americans." Social Work 40, no. 2:240-48. Donohue, John J. III and Steven D. Levitt. 2001 "The Impact of Race on Policing and Arrests," The Journal of Law and Economics 44, no. 2: 367-394.

English Devin, Sharon F. Lambert, Michele K. Evans, Alan B. Zonderman. 2014. "Neighborhood racial composition, racial discrimination, and depressive symptoms in African Americans." American Journal of Community Psychology. 54(3-4):219228. doi: 10.1007/s10464-014-9666-y.

FREY, WILLIAM H. 2015. Diversity Explosion: How New Racial Demographics Are Remaking America. Washington D.C.: Brookings Institution Press.

Glikman, A. and Semyonov, M. 2012. "Ethnic Origin and Residential Attainment of Immigrants in European Countries." City \& Community, 11: 198-219. doi:10.1111/j.1540-6040.2012.01398.x

Goosby, Bridget; \& Walsemann, Katrina. 2012. "School racial composition and race/ethnic differences in early adulthood health." Health and Place, 188(2), 296304. PMCID: PMC3274606 NIHMSID: NIHMS334248

Grayman-Simpson, Nyasha, and Jacqueline S. Mattis. 2013. "'If It Wasn't for the Church...:" Organizational Religiosity and Informal Community Helping among African American Adults." Journal of African American Studies 17, no. 3: 243-52. http://www.jstor.org/stable/43526414.

Green, Donald P., Dara Z. Strolovitch, and Janelle S. Wong. 1998. "Defended Neighborhoods, Integration, and Racially Motivated Crime." American Journal of Sociology 104, no. 2 372-403. doi:10.1086/210042. 
GRUBER, JAMES E. 1998. "The Impact of Male Work Environments and Organizational Policies on Women's Experiences of Sexual Harassment." Gender \& Society 12, no. 3 301-20. doi:10.1177/0891243298012003004.

Hanushek, Eric A., John F. Kain, and Steven G. Rivkin, 2009. "New Evidence about Brown v. Board of Education: The Complex Effects of School Racial Composition on Achievement," Journal of Labor Economics 27, no. 3: 349-383

Hastings, J., Kane, T., and Staiger, D. 2008. "Heterogeneous Preferences and the Efficacy of Public School Choice." NBER Working Paper 2145 and Working Paper 11805 combined.

Heilman, M. E., Wallen, A. S., Fuchs, D., \& Tamkins, M. M. 2004. Penalties for Success: Reactions to Women Who Succeed at Male Gender-Typed Tasks. Journal of Applied Psychology, 89(3), 416-427. http://dx.doi.org/10.1037/0021-9010.89.3.416

Hurd, Noelle M., Robert M. Sellers, Cmytney D. Cogburn, Sheretta T. ButlerBarnes, \& Marc A. Zimmerman. 2013. "Racial identity and depressive symptoms among Black emerging adults: The moderating effects of neighborhood racial composition.” Developmental Psychology, 49(5), 938-950.

Inzlicht, Michael, Joshua Aronson, Catherine Good, \& Linda McKay. 2006. "A particular resiliency to threatening environments." Journal of Experimental Social Psychology, 42(3), 323-336.

Jargowsky Paul. 1996. "Take the Money and Run: Economic Segregation in US Metropolitan Areas." American Sociological Review. 61:984-98.

Keels, Micere, Greg J. Duncan, Stefanie Deluca, Ruby Mendenhall, and James Rosenbaum. 2005. "Fifteen Years Later: Can Residential Mobility Programs Provide a Long-Term Escape from Neighborhood Segregation, Crime, and Poverty?" Demography42, no. 1: 51-73. http://www.jstor.org/stable/1515176. 
Keels, Micere. 2008. "Second-Generation Effects of Chicago's Gautreaux Residential Mobility Program on Children's Participation in Crime.” Journal of Research on Adolescence. 18(2), 305-352.

Klonoff, Elizabeth A., \& Hope A. Landrine. 1999. “Acculturation and alcohol use among blacks: The benefits of remaining culturally traditional.” The Western Journal of Black Studies, 23, 211-216.

Krysan, Maria, and Kyle Crowder. 2017.Cycle of Segregation: Social Processes and Residential Stratification. New York: Russell Sage Foundation. http://www.jstor.org/stable/10.7758/9781610448697.

Krysan Maria, Reynolds Farley. 2002. "The Residential Preferences of Blacks: Do They Explain Persistent Segregation?" Social Forces. 80(3):937-980.

Landrine, Hope, \& Elizabeth A. Klonoff. 2004. "Culture change and ethnic-minority health behavior: An operant theory of acculturation." Journal of Behavioral Medicine, 27, 527-555.

Liebow, Elliot. 1967. Tally's Corner: A Study of Negro Streetcorner Men. Boston: Little, Brown and Company

Lyons, Christopher J. 2008. "Defending Turf: Racial Demographics and Hate Crime Against Blacks and Whites" Social Forces, Volume 87, Issue 1, Pages 357-385, https://doi.org/10.1353/sof.0.0071

Massey, Douglas S. 1990. "American Apartheid: Segregation and the Making of the Underclass." American Journal of Sociology 96, no. 2: 329-57.

http://www.jstor.org/stable/2781105.

Massey, Douglas S. 1995. "Getting Away with Murder: Segregation and Violent Crime in Urban America." University of Pennsylvania Law Review 143, no. 5: 1203232. doi:10.2307/3312474. 
Mendenhall, Ruby, Stephanie DeLuca, Greg Duncan 2006. "Neighborhood resources, racial segregation, and economic mobility: Results from the Gautreaux program” Social Science Research, 35 pp. 892-923

Nettles, Michael T., A. Robert Thoeny, and Erica J. Gosman. 1986. "Comparative and Predictive Analyses of Black and White Students' College Achievement and Experiences." The Journal of Higher Education 57, no. 3 289-318. doi:10.2307/1981554.

Pattillo-McCoy, Mary. 1998. "Church Culture as a Strategy of Action in the Black Community." American Sociological Review 63, no. 6: 767-84. http://www.jstor.org/stable/2657500.

Petersen, Trond, and Laurie A. Morgan. 1995."Separate and Unequal: OccupationEstablishment Sex Segregation and the Gender Wage Gap." American Journal of Sociology 101, no. 2 329-65. http://www.jstor.org/stable/2782431.

Pfeiffer, Deirdre. 2012. "African Americans' Search for 'More for Less' and 'Peace of Mind' on the Exurban Frontier." Urban Geography 33(1): 64-90.

Popkin, S., Rosenbaum, J. E. and Meaden, P. 1993. Labor market experiences of low-income black women in middle-class suburbs: evidence from a survey of Gautreaux program participants. Journal of Policy Analysis and Management, 12: $556-573$.

Popkin, Susan J., James E. Rosenbaum and Stefanie DeLuca. 2010. "What Kinds of Neighborhoods Change Lives? the Chicago Gautreaux Housing Program and Recent Mobility Programs."

Postmes, Tom, \& Nyla R. Branscombe. 2002. "Influence of long-term racial environmental composition on subjective Well-being in African Americans." Journal of Personality and Social Psychology, 83(3), 735-751. 
Rosenbaum, James E. 1992. "Black Pioneers--Do Their Moves to the Suburbs Increase Economic Opportunity for Mothers and Children?" Housing Policy Debate 2: $1179-1213$.

Rosenbaum, James E., Susan J. Popkin, Julie E. Kaufman, and Jennifer Rusin. 1991. "Social Integration of Low-Income Black Adults in Middle-Class White Suburbs." Social Problems 38, no. 4: 448-61. doi:10.2307/800564.

Sampson, R. J., Sharkey, P., \& Raudenbush, S. W. 2008. Durable effects of concentrated disadvantage on verbal ability among African-American children. Proceedings of the National Academy of Sciences of the United States of America, 105(3), 845-852. doi:10.1073/pnas.0710189104

Sharkey, Patrick and Felix Elwert. 2011. "The Legacy of Disadvantage:

Multigenerational Neighborhood Effects on Cognitive Ability." American Journal of Sociology 116(6):1934-81.

Sharkey, Patrick. 2012. "An Alternative Approach to Addressing Selection Into and Out of Social Settings: Neighborhood Change and African American Children's Economic Outcomes." Sociological Methods \& Research 41(2):251-93.

Shorter-Gooden, K. 2004. "Multiple resistance strategies: How African American women cope with racism and sexism." Journal of Black Psychology, 30(3), 406-425.

Sidanius, Jim; Pratto, Felicia 1999. Social Dominance: An Intergroup Theory of Social Hierarchy and Oppression. Cambridge: Cambridge University Press. ISBN 978-0-521-62290-5.

Smith, Jessi L., and Meghan Huntoon. 2014. "Women's Bragging Rights:

Overcoming Modesty Norms to Facilitate Women's Self-Promotion.” Psychology of Women Quarterly 38, no. 4 447-59. doi:10.1177/0361684313515840.

Smith, Jessi L., Karyn L. Lewis, Lauren Hawthorne, and Sara D. Hodges. 2013. “When Trying Hard Isn't Natural: Women's Belonging With and Motivation for Male-Dominated STEM Fields As a Function of Effort Expenditure Concerns.” 
Personality and Social Psychology Bulletin 39, no. 2 131-43.

doi:10.1177/0146167212468332.

Stack, Carol. 1974. All our kin. New York: Basic Books.

Stainback, Kevin, Matthew Irvin. 2012. "Workplace racial composition, perceived discrimination, and organizational attachment." Social Sci. Res.

doi:10.1016/j.ssresearch.2011.11.016

Stephens-Davidowitz, Seth I., The Cost of Racial Animus on a Black Presidential Candidate: Using Google Search Data to Find What Surveys Miss (March 24, 2013). Available at SSRN: https://ssrn.com/abstract=2238851 or http://dx.doi.org/10.2139/ssrn.2238851

Stipak, Brian, and Carl Hensler. 1983. "Effect of Neighborhood Racial and Socioeconomic Composition on Urban Residents' Evaluations of Their Neighborhoods." Social Indicators Research 12, no. 3: 311-20. http://www.jstor.org/stable/27521104.

Stock, Michelle L., Frederick X. Gibbons, Meg Gerrard, Amy E. Houlihan, ChihYuan Weng, Fred O. Lorenz, \& Ronald L. Simons. 2013. "Racial identification, racial composition, and substance use vulnerability among African American adolescents and young adults." Health Psychology, 32(3), 237-247. http://dx.doi.org/10.1037/a0030149

Terhune, Carol Parker. 2008. "Coping in Isolation: The Experiences of Black Women in White Communities." Journal of Black Studies38, no. 4 : 547-64. http://www.jstor.org/stable/40034421.

Vogt Yuan, Anastasia S. 2007. "RACIAL COMPOSITION OF NEIGHBORHOOD AND EMOTIONAL WELL-BEING," Sociological Spectrum, 28:1, 105-129, DOI: 10.1080/02732170701675284 


\section{Appendix}

\section{Multi-City Study on Urban Inequality Questions}

\section{Question used to Proxy DRD}

"Next, for each group I want to know whether you think they tend not to be involved in drugs and gangs or tend to be involved in drugs and gangs. Where would you rate (GROUP) on this scale, where 1 means tends not to be involved with drugs and gangs and 7 means tends to be involved with drugs and gangs? A score of 4 means you think the group is not towards one end or the other and, of course, you may choose any number in between that comes closest to where you think people in the group stand."

$\underline{\text { Question used to Proxy IRD }}$

"Finally, for each group I want to know whether you think they tend to treat members of other groups equally or tend to discriminate against members of other groups. Where would you rate (GROUP) on this scale, where 1 means tends to treat members of other groups equally and 7 means tends to discriminate against other groups? A score of 4 means you think that the group is not toward one end or the other and, of course, you may choose any number in between that comes closest to where you think people in the group stand." 


\section{Tables}

Table One

\begin{tabular}{|r|r|l|}
\hline Black Proportion & Utility & Percent Choose \\
\hline $0 \%$ & 10 & 20 \\
\hline $25 \%$ & 10 & 20 \\
\hline $50 \%$ & 10 & 20 \\
\hline $75 \%$ & 10 & 20 \\
\hline $100 \%$ & 10 & 20 \\
\hline
\end{tabular}

Table Two

\begin{tabular}{|r|r|r|}
\hline Black Proportion & Utility & Percent Choose \\
\hline $0 \%$ & 10 & 71.488 \\
\hline $25 \%$ & 8.75 & 20.482 \\
\hline $50 \%$ & 7.5 & 5.868 \\
\hline $75 \%$ & 6.25 & 1.681 \\
\hline $100 \%$ & 5 & 0.482 \\
\hline
\end{tabular}

Table Three

\begin{tabular}{|r|r|r|}
\hline Black Proportion & Utility & Percent Choose \\
\hline $0 \%$ & 5 & 0.482 \\
\hline $25 \%$ & 6.25 & 1.681 \\
\hline $50 \%$ & 7.5 & 5.868 \\
\hline $75 \%$ & 8.75 & 20.482 \\
\hline $100 \%$ & 10 & 71.488 \\
\hline
\end{tabular}

Table Four

\begin{tabular}{|c|c|c|}
\hline Black Proportion & Utility & Percent Choose \\
\hline $0 \%$ & & $\begin{array}{lll}5 & 20\end{array}$ \\
\hline $25 \%$ & & 520 \\
\hline $50 \%$ & & 520 \\
\hline $75 \%$ & & 520 \\
\hline $100 \%$ & & 520 \\
\hline
\end{tabular}


Table Five

High-Directly-Related

Low Directly-Related Disadvantages Disadvantages

Low Inversely-Related

Disadvantages

$U=13.146\left(p_{B}\right)-10.29362\left(p_{B}\right)^{2} \quad U=12.63898\left(p_{B}\right)-10.2636\left(p_{B}\right)^{2}$

High Inversely-Related

Disadvantages

$U=12.21941\left(p_{B}\right)-9.276859\left(p_{B}\right)^{2} U=11.77774\left(p_{B}\right)-9.45232\left(p_{B}\right)^{2}$

Table Six - Percent of Blacks that would Choose 100\% black neighborhood over 0\% black neighborhood

\begin{tabular}{|l|l|l|}
\hline & \multicolumn{1}{|c|}{$\begin{array}{l}\text { High-Directly-Related } \\
\text { Lisadvantages }\end{array}$} \\
\hline $\begin{array}{l}\text { Low Inversely-Related } \\
\text { Disadvantages }\end{array}$ & $94.54 \%(2.8524)$ & $91.78 \%(2.4126)$ \\
\hline $\begin{array}{l}\text { High Inversely-Related } \\
\text { Disadvantages }\end{array}$ & $94.99 \%(2.9426)$ & $91.10 \%(2.3254)$ \\
\hline
\end{tabular}

Table Seven - Percent of Blacks that would Choose 100\% black neighborhood over $25 \%$ black neighborhood

\begin{tabular}{|c|c|c|}
\hline & Low Directly-Related Disadvantages & $\begin{array}{l}\text { High-Directly-Related } \\
\text { Disadvantages }\end{array}$ \\
\hline $\begin{array}{l}\text { Low Inversely-Related } \\
\text { Disadvantages }\end{array}$ & $55.21 \%$ & $47.30 \%$ \\
\hline $\begin{array}{l}\text { High Inversely-Related } \\
\text { Disadvantages }\end{array}$ & $61.48 \%$ & $49.29 \%$ \\
\hline
\end{tabular}

Table Eight - Percent of Blacks that would Choose 100\% black neighborhood over $50 \%$ black neighborhood 
High-Directly-Related

Low Directly-Related Disadvantages Disadvantages

Low Inversely-Related

Disadvantages

$24.10 \%$

$20.58 \%$

High Inversely-Related

Disadvantages

$29.99 \%$

$23.14 \%$

Table Nine - Percent Black Neighborhood with Equivalent Utility to 100\% Black

Neighborhood

\begin{tabular}{|l|l|l|}
\hline & Low Directly-Related Disadvantages & $\begin{array}{l}\text { High-Directly-Related } \\
\text { Disadvantages }\end{array}$ \\
\hline $\begin{array}{l}\text { Low Inversely-Related } \\
\text { Disadvantages }\end{array}$ & $27.710 \%(2.85238)$ & $23.144 \%(2.37538)$ \\
\hline $\begin{array}{l}\text { High Inversely-Related } \\
\text { Disadvantages }\end{array}$ & $31.719 \%(2.942551)$ & $24.602 \%(2.32542)$ \\
\hline
\end{tabular}

Table Ten

Mean $\quad$ SD $\quad$ Min $\quad$ Max

$\begin{array}{llcrr}\text { Racism } & 45.9918 & 11.93681 & 20 & 80 \\ \text { Inv. BRI } & .5306032 & .0731318 & .3725226 & .7400917\end{array}$

Observations $\quad 122$ 


\section{Table Eleven}

Neighborhood Proportion Black - Affluent Blacks 2016

(1)

Neigh. PB 2016

\begin{tabular}{|c|c|}
\hline \multirow[t]{2}{*}{ Racism } & $-0.144^{\star}$ \\
\hline & $(-2.00)$ \\
\hline \multirow[t]{2}{*}{ Racism^2 } & $0.00200 *$ \\
\hline & $(2.39)$ \\
\hline \multirow[t]{2}{*}{ Inv. BRI } & $-10 \cdot 45$ \\
\hline & $(-1.87)$ \\
\hline \multirow[t]{2}{*}{ Inv $\cdot B R I^{\wedge} 2$} & $11.23^{*}$ \\
\hline & $(2.22)$ \\
\hline \multirow[t]{2}{*}{ Racism X Inv. BRI } & $0.611 \star$ \\
\hline & $(2.28)$ \\
\hline \multirow[t]{2}{*}{ Racism X Inv. BRI^2 } & $-0.648 * *$ \\
\hline & $(-2.64)$ \\
\hline \multirow[t]{2}{*}{ Racism^2 X Inv. BRI } & $-0.00838 * *$ \\
\hline & $(-2.67)$ \\
\hline \multirow[t]{2}{*}{ Racism^2 X Inv. BRI^2 } & $0.00875 * \star$ \\
\hline & $(3.02)$ \\
\hline \multirow[t]{2}{*}{ Neigh. PB 2009} & $0.880 * * *$ \\
\hline & $(36.75)$ \\
\hline \multirow[t]{2}{*}{ Change in DMA Proportion Black } & $0.818 *$ \\
\hline & $(2.30)$ \\
\hline \multirow[t]{2}{*}{ Google Control \#1 } & 0.000198 \\
\hline & $(0.48)$ \\
\hline \multirow[t]{2}{*}{ Google Control \#2 } & $0.00127 * * *$ \\
\hline & $(4.46)$ \\
\hline \multirow[t]{2}{*}{ Google Control \#3 } & -0.000452 \\
\hline & $(-1 \cdot 30)$ \\
\hline \multirow[t]{2}{*}{ Constant } & 2.417 \\
\hline & $(1.60)$ \\
\hline Observations & 122 \\
\hline Adjusted R-squared & 0.961 \\
\hline
\end{tabular}

$t$ statistics in parentheses

* $\mathrm{p}<0.05, * * \mathrm{p}<0.01, * * * \mathrm{p}<0.001$ 
Figures

Figure One

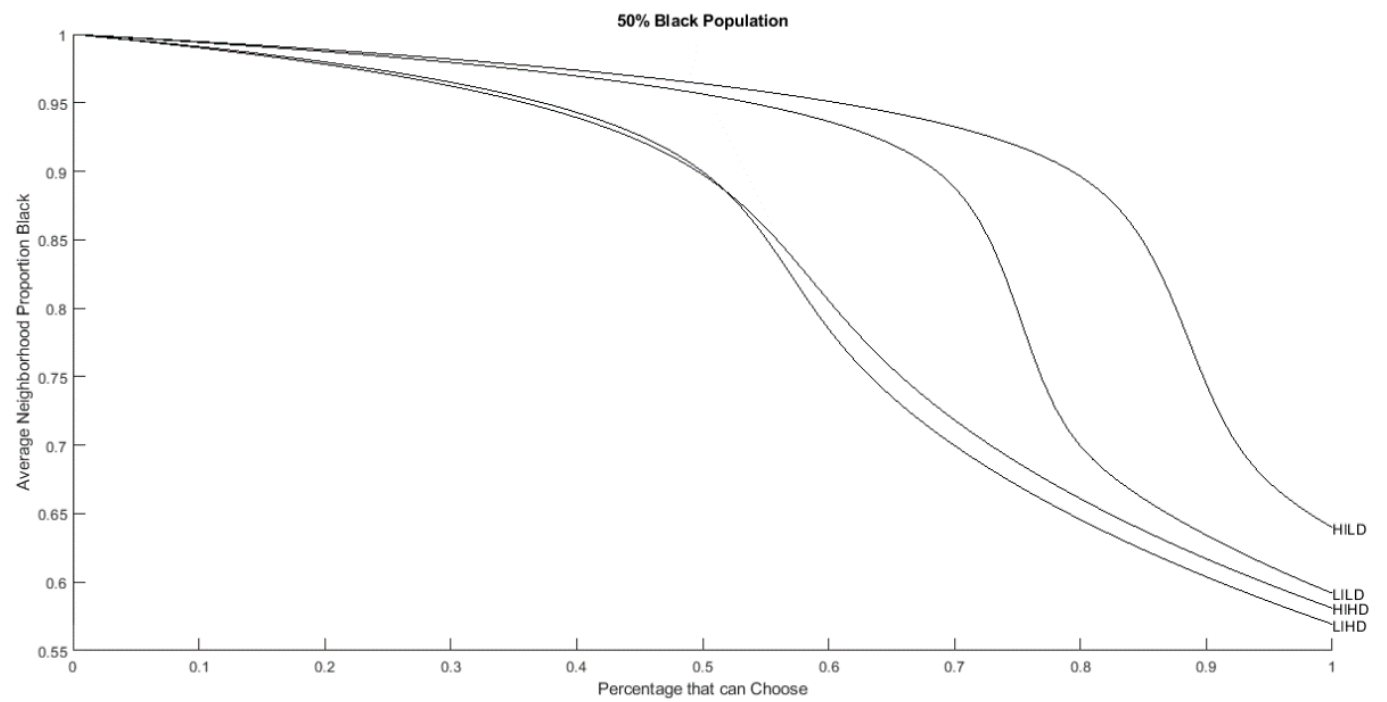

Figure Two

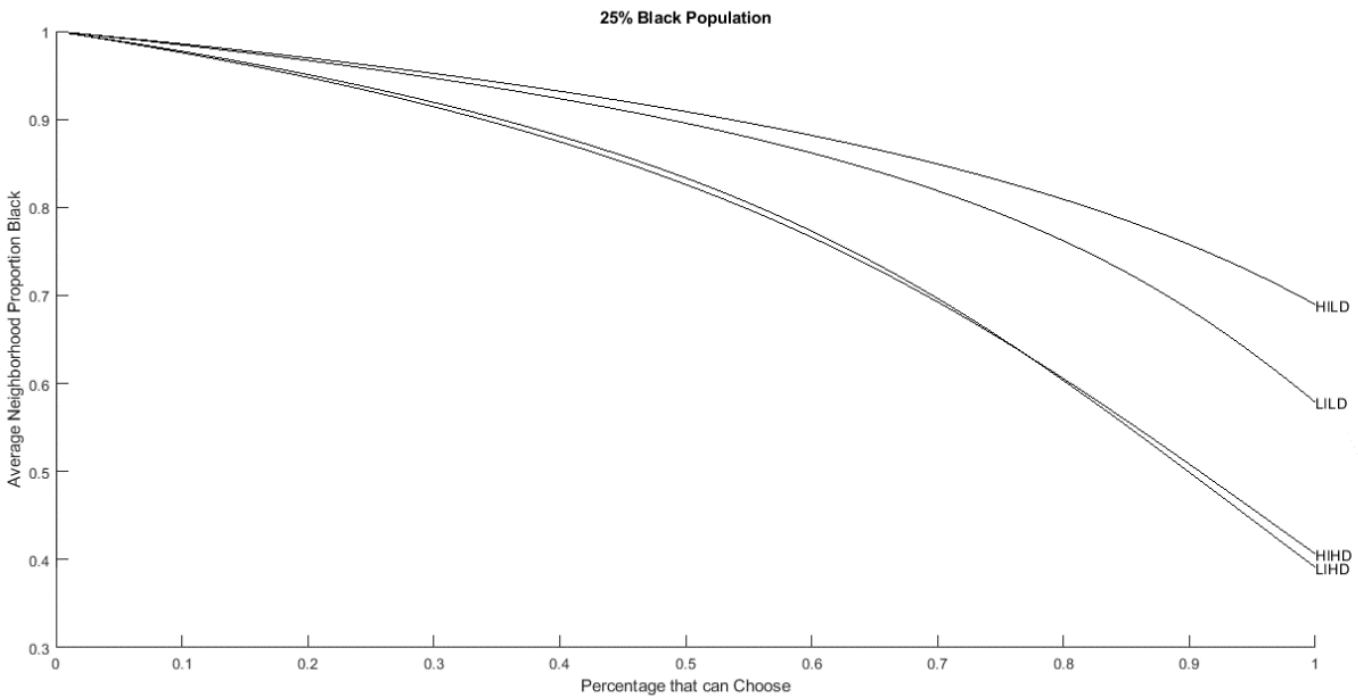

Figure Three 


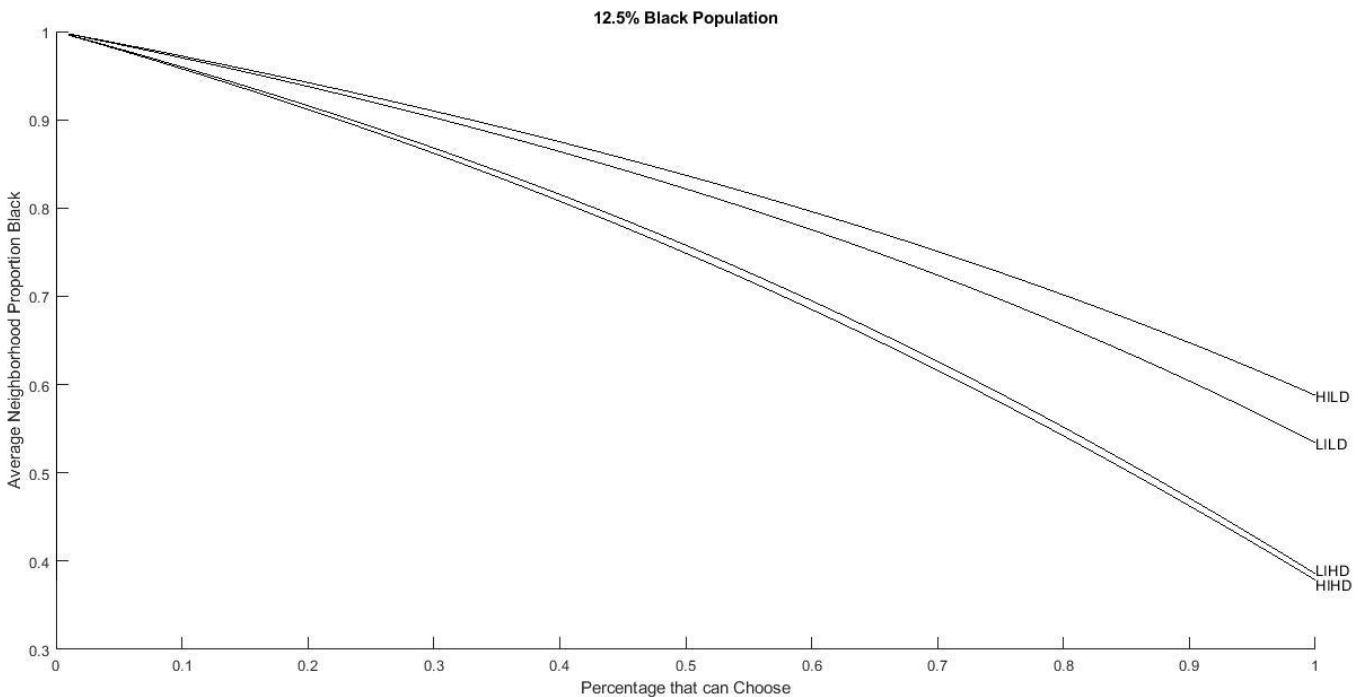

Figure Four

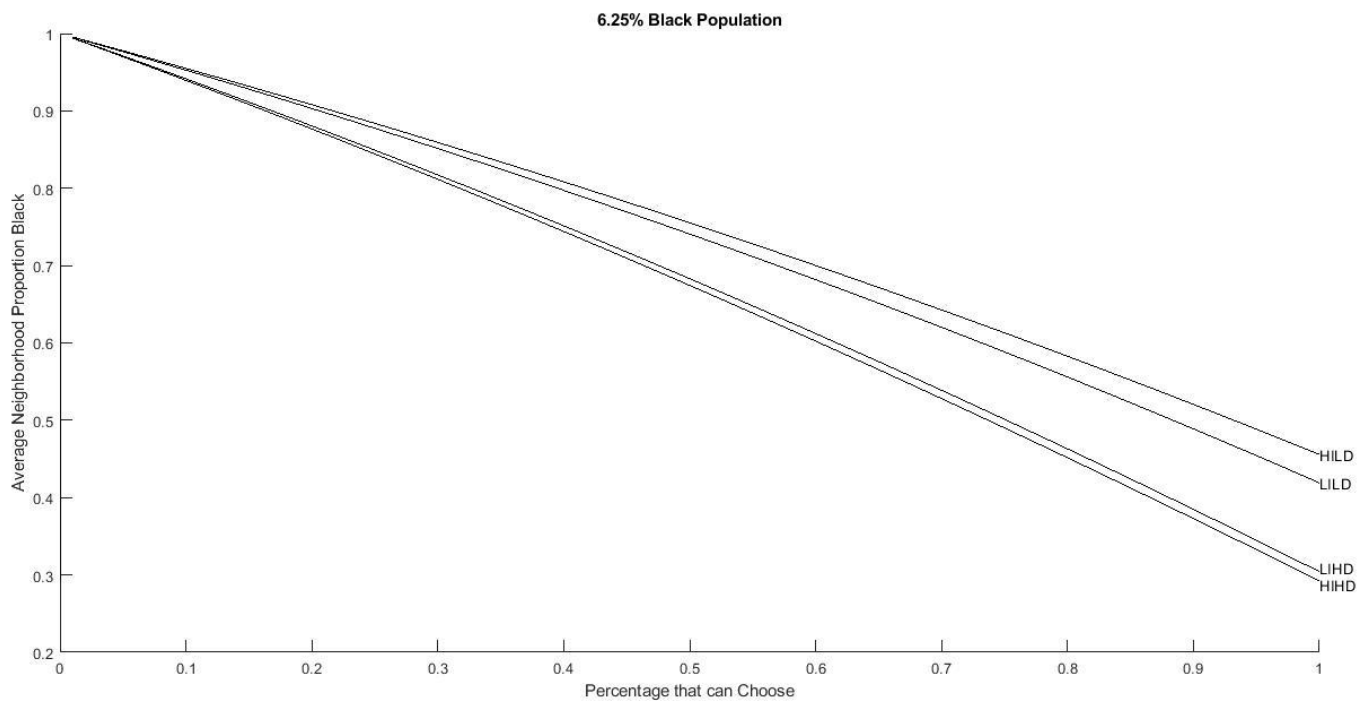

Figure Five 


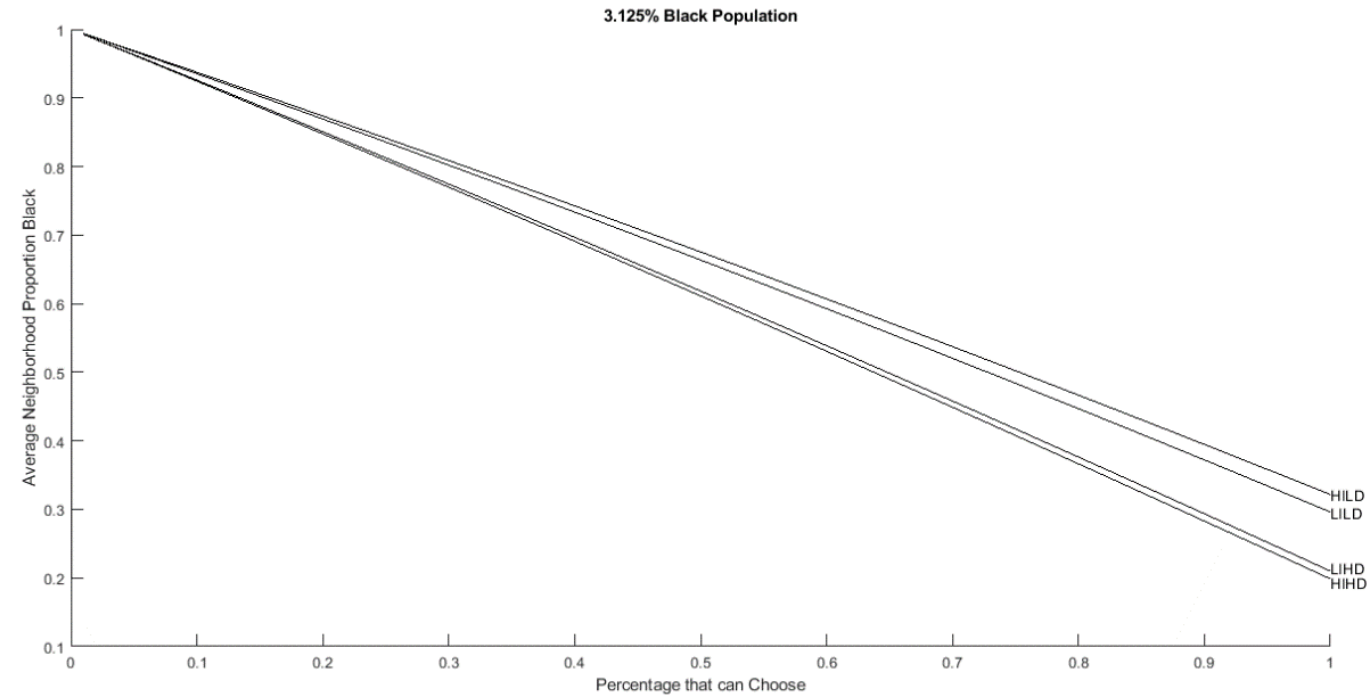

Figure Six

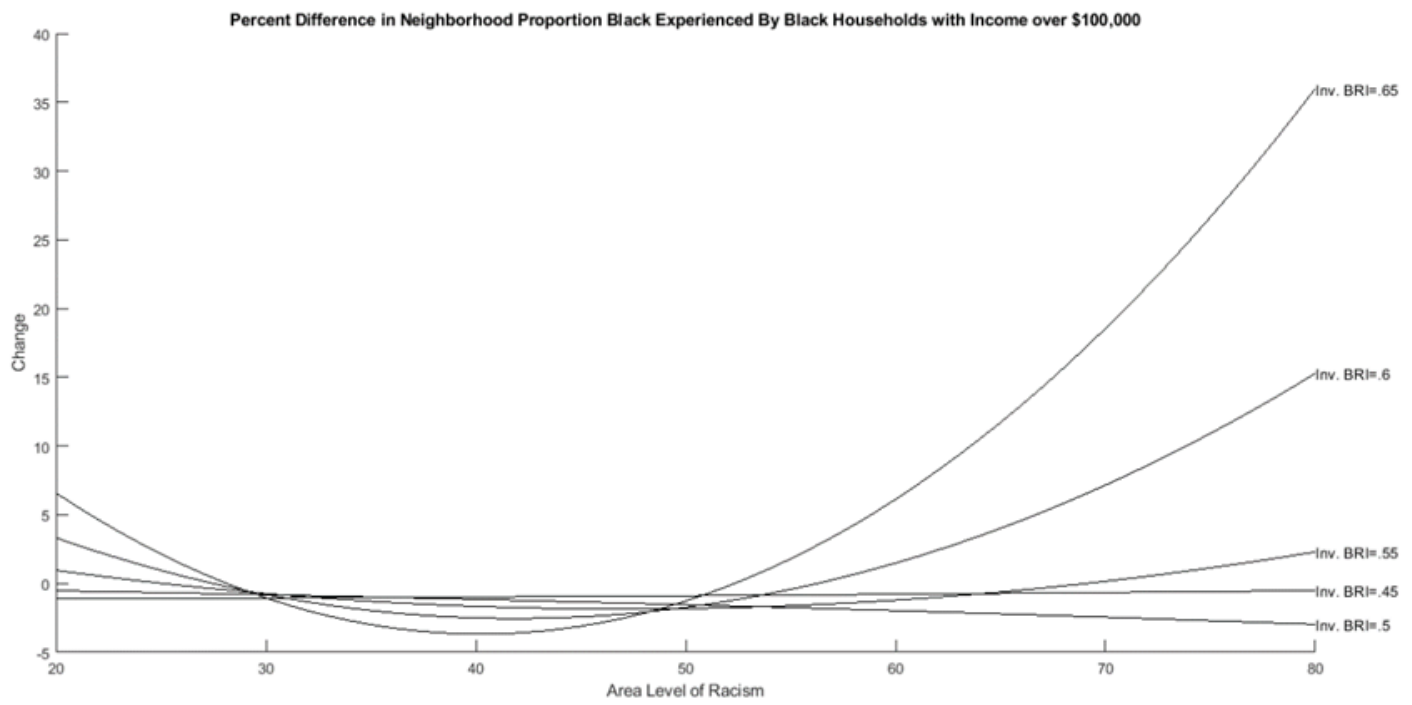

